\title{
A risk-based scoring system to quantify biosecurity in cattle production
}

\author{
Bert Damiaans $^{\mathrm{a}, *}$, Véronique Renault ${ }^{\mathrm{b}}$, Steven Sarrazin ${ }^{\mathrm{a}}$, Anna Catharina Berge ${ }^{\mathrm{a}}$, Bart Pardon ${ }^{\mathrm{c}}$, \\ Claude Saegerman ${ }^{\mathrm{b}}$, Jeroen Dewulf ${ }^{\mathrm{a}}$ \\ ${ }^{a}$ Veterinary Epidemiology Unit, Department of Reproduction, Obstetrics and Herd Health, Faculty of Veterinary Medicine, Ghent University, Salisburylaan 133, 9820 \\ Merelbeke, Belgium \\ ${ }^{\mathrm{b}}$ Research Unit in Epidemiology and Risk Analysis Applied to Veterinary Sciences (UREAR), Faculty of Veterinary Medicine, University of Liege, Belgium \\ ${ }^{\mathrm{c}}$ Department of Large Animal Internal Medicine, Faculty of Veterinary Medicine, Ghent University, Salisburylaan 133, 982017 Merelbeke, Belgium
}

\section{A R T I C L E I N F O}

\section{Keywords:}

Biosecurity

Cattle

Risk-scoring tool

Questionnaire

Evaluation

\begin{abstract}
A B S T R A C T
Farm biosecurity includes all measures preventing pathogens from entering (external) and spreading within a herd (internal) and is important in facilitating the shift from cure to prevention in veterinary medicine. To assess biosecurity on farm level quantitatively an objective measurement process is required. This study describes the development and implementation of risk-based weighted biosecurity evaluation tools for veal, beef and dairy cattle farms. Based on risk factors and biosecurity measures associated with priority cattle diseases and the results of a cross-sectional survey on Belgian farms, questions were selected for the Biocheck-tool. The scoring system consists of three separate questionnaires that contain 69 (veal), 104 (beef) and 124 (dairy) questions. Experts in various fields of veterinary medicine were asked to weigh the different biosecurity categories and questions according to the method of Gore. The system obtained provides biosecurity scores per category (external and internal biosecurity) and subcategory (e.g. purchase, transport, health management). The Biocheck tool was subsequently used in a survey to assess biosecurity in 20 veal, 50 beef and 50 dairy farms. For all production systems, both internal and external biosecurity were considered low, resulting in low mean total biosecurity scores of 39.7 points for veal (SD $=7.4), 44.3$ for beef (SD $=8.4$ ), and 48.6 points for dairy farms $(S D=8.1)$, out of a maximum of 100 points. For all farm types, the scores for internal biosecurity were lower compared to external biosecurity. Veal farms scored significantly lower for "purchase" than beef and dairy, while scoring higher for the other subcategories of external biosecurity. In dairy and beef, "purchase and reproduction" was the highest scoring subcategory. For internal biosecurity, "health management" was particularly low in the three farm types, while subcategories exceeding 50 points were rare. With this tool, implementation of biosecurity on cattle farms can be assessed in a standardized and reproducible manner. This evaluation allows for benchmarking of farms and herd-specific advice for improvements.
\end{abstract}

\section{Introduction}

In intensive cattle production, the incidence of infectious diseases plays an important role in profitability. Damage incurred by disease can cause severe direct and indirect economical losses due to reduced growth and/or production rate, impaired fertility, or increased susceptibility to other diseases (Enting et al., 1997; Houe, 1999; Daugschies and Najdrowski, 2005). Therefore, disease prevention is preferred above cure as stated by the European Council Regulation (2016). Biosecurity includes all measures preventing pathogens from entering (external biosecurity) and spreading within a herd (internal biosecurity) (Lin et al., 2003; Villarroel et al., 2007; Damiaans et al., 2018; Dewulf and Van Immerseel, 2018) and is seen as a cornerstone of preventive medicine. In several production systems, it has already been demonstrated that improved biosecurity may result in improved animal health and welfare, improved productivity, reduced antimicrobial use and the consequential selection for antimicrobial resistance (Mellor and Stafford, 2004; Gunn et al., 2008; Brennan and Christley, 2013; Sarrazin et al., 2014; Nöremark et al., 2016; Damiaans et al., 2018; Postma and Dewulf, 2018).

Despite these positive impacts of biosecurity measures, previous studies have shown that the implementation of biosecurity measures in cattle farms is often limited (Nöremark et al., 2010; Sarrazin et al., 2014; Renault et al., 2018a; Damiaans et al., 2019). Frequently mentioned reasons for these low levels of biosecurity are the expected required investment in labor, time and capital (Damiaans et al., 2018).

\footnotetext{
* Corresponding author.

E-mail address: bert.damiaans@ugent.be (B. Damiaans).
} 
Yet, often these hurdles are based on perception and lack of correct information. Therefore, to enable farmers to implement biosecurity, there is a need to provide accessible and practical information on biosecurity (Gunn et al., 2008; Brennan and Christley, 2013; Sayers et al., 2014; Nöremark et al., 2016; Damiaans et al., 2018).

The lack of quantitative data truly linking biosecurity with improved health and production may also explain the low implementation of biosecurity. Although multiple risk factors and biosecurity measures have been described in literature, they usually focus on a single disease (Maunsell and Donovan, 2009; Rehman et al., 2011; Humphry et al., 2012). Unlike for pig and poultry industries, the relationship between an overall biosecurity level and other farm characteristics such as animal health, technical parameters and antimicrobial use has not been evaluated in cattle production. This is partially due to the absence of a quantitative way to measure biosecurity on cattle farms. For pigs and poultry, the risk-based biosecurity scoring system Biocheck.UGent was developed (Laanen et al., 2013; Gelaude et al., 2014).

To enable quantification of biosecurity in cattle production, the aim of this study was to develop and evaluate a risk-based weighted biosecurity evaluation tool for dairy, beef and veal cattle production.

\section{Materials and methods}

\subsection{Development of a biosecurity scoring system}

\subsubsection{Biosecurity questionnaire}

To assess biosecurity on different types of cattle farms, the Biocheck Cattle tool was developed in several steps. In a first step, a biosecurity questionnaire was drafted. This questionnaire was based on a list of 47 priority diseases for cattle and the risk factors and biosecurity measures associated with these diseases (Renault et al., 2018b). The questionnaire consisted of 19 categories with a total of 304 questions and can be found in Annex 1 (Renault et al., 2018a; Damiaans et al., 2019).

After pilot testing, this questionnaire was used in a survey of 20 randomly selected veal farms, 50 dairy and 50 beef farms in Belgium. In a random sample of all Belgian farms, each farm was assigned a number and subsequently sorted. Farmers were contacted in that order. If the farmer agreed, a farm visit was made to fill in the questionnaire after observing biosecurity practices and measures on the farm. This was done to minimize reporting bias. Using the results from this survey together with the information previously gained by the literature review, questions were selected for the Biocheck Cattle-tool according to the procedure in Fig. 1. First, all questions to which no clear score could be assigned were removed from the questionnaire, e.g. breed was a risk factor, but one breed could not be considered better than another, so a higher score could not be assigned to a certain breed. Next, all questions with less than $15 \%$ variation in the application of the corresponding biosecurity measures in the survey were removed, except for the questions based on risk factors relevant for multiple diseases or highly stressed by multiple sources in the literature review. These questions were considered too important to remove even if the implementation varied little. For each question, the correlation with the other questions within the same category was calculated. Possible correlations between questions of different categories were also explored. For continuous variables, the Pearson correlation was calculated, while for ordinal and dichotomous variables the Spearman correlation was used. This process was carried out separately for veal, beef and dairy farms. If a correlation between two questions was larger than 0.5 and biologically explainable, the question containing the least information was removed. Through this approach, the number of questions was reduced to the minimum number required to achieve a full evaluation of all relevant aspects of biosecurity on the farm.

As the veal, dairy and beef industry are inherently different, three different questionnaires were developed. For some biosecurity components, the questions are very comparable across the sectors, whereas for other components a different approach is used.
Each of the questionnaires was divided into the main categories external and internal biosecurity. The category external biosecurity was divided into five subcategories: "purchase and reproduction", "transport and carcass removal", "feed and water", "visitors and employees" and "vermin control and other animals". Internal biosecurity was divided into three to six subcategories: "health management", "calving management" (only beef and dairy), "calf management", "dairy management" (only dairy), "adult cattle management" (only beef and dairy) and "working organization and equipment". The resulting questionnaires are available in English, Dutch and French and can be consulted on the website: http://www.biocheck.ugent.be and in Annex 2.

\subsubsection{Prioritization of different biosecurity measures}

Some transmission routes are more probable to transmit disease than others (Gelaude et al., 2014; Dewulf and Van Immerseel, 2018; Sarrazin et al., 2018). Therefore not all biosecurity measures are equally important. Besides the importance, also the frequency of occurrence of the risk will influence the likelihood of transmission (Dewulf and Van Immerseel, 2018). Therefore, different biosecurity measures should receive different weights in accordance with the importance of the prevented transmission route and the frequency of occurrence of the risk. To achieve this, the biosecurity measures were weighted according to their relative importance as previously done for the pig (Laanen et al., 2013) and poultry industries (Gelaude et al., 2014).

To obtain the weights, fourteen experts, including epidemiologists $(n=2)$, sector-specific experts $(n=3$; for dairy, beef and veal), European board certified specialists in herd health management $(\mathrm{n}=$ $5)$, hygiene $(n=2)$ and infectious disease specialists $(n=3)$ were asked to weigh the different biosecurity categories, depending on their perceived importance in disease prevention. This was done according to the method of Gore (1987) in which the experts had to distribute a total of 100 points over the subcategories in proportion to their perceived importance, for external (five subcategories) and internal biosecurity (six subcategories) separately.

Once the weight of each subcategory was determined, the separate questions within each subcategory were also weighted according to the same principles (importance and frequency of occurrence). This weighting was done by a separate group of five experts included in the author list again according to the method of Gore (1987) resulting in a distribution of 100 points per subcategory. The final weights per question were determined in consensus after face-to-face discussion among the five experts.

\subsubsection{Operation of the scoring system}

The answer describing the ideal biosecurity situation always received the full points of the question, while less optimal answers received less or no points. For most questions only two scores were available (measure present or absent). In a minority of the cases an intermediate score was provided. For some questions three or more answering options (e.g. always, sometimes, never) were foreseen, yet for most of these questions only two scores were available as the intermediate answer (e.g. sometimes) was scored equal to the lowest scoring answer.

Some of the questions can only be answered when a prerequisite is fulfilled in one of the previous questions. When these conditional questions followed the answer that describes the ideal biosecurity situation, no issues in the scoring arose. For example, cleaning of the quarantine stable could not be executed if no quarantine stable was available. The points for cleaning could only be earned if the question for presence of a quarantine stable was answered positively. However, when the conditional questions followed after the choice of a less optimal answer, then the score of the answer describing the ideal situation was higher than the sum of the scores of the less optimal answer and the conditional questions. For example, following the least optimal answer (Yes) to the question if animals are purchased, 13 conditional questions 


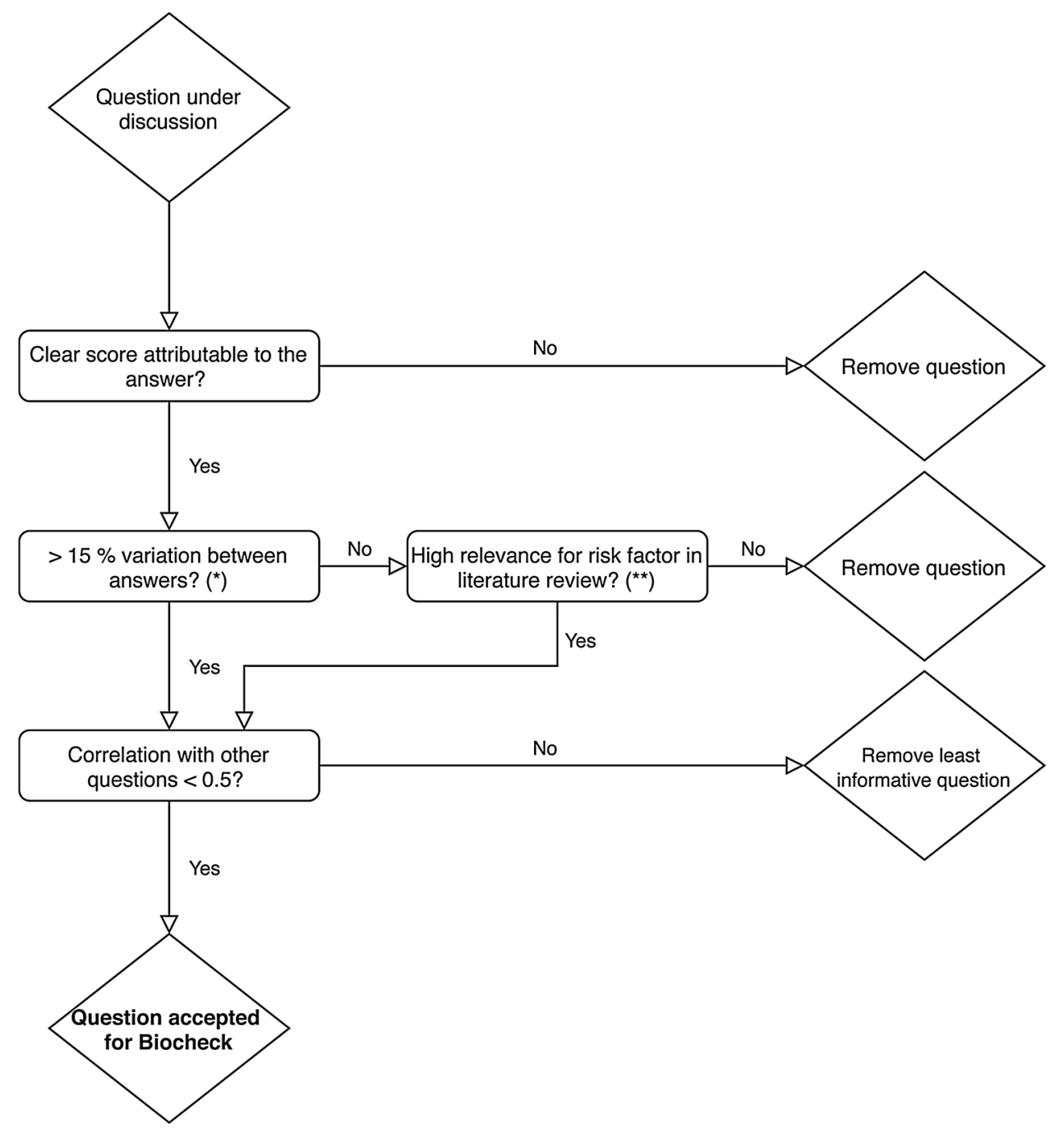

Fig. 1. Flowchart describing the selection proces for a question to be selected for the Biocheck tool.

represented a possible total of 75 points. These questions did not appear after the ideal answer (No) as they were not applicable, consequently these 75 points could not be earned. Therefore to this answer 79 points were awarded. These 79 points consist of the four points awarded to the question itself and 75 points that could not be earned because the questions were not asked. The rest of the points (21) could be earned through unconditional questions. Otherwise the ideal biosecurity situation would not reach the maximum of 100 points.

The total score of a subcategory was achieved by adding all scores of the individual questions. The weights of the questions were distributed in such a way that in the optimal situation (=implementation of all biosecurity measures) the total score added up to 100 points, whereas in the worst situation (=none of the biosecurity measures implemented) the total score equaled zero points. The scores for external and internal biosecurity were obtained by taking the weighted averages (according to the weights of the subcategories) of all subcategories included. The overall biosecurity score was calculated by taking the weighted scores of all the subcategories. To illustrate the operation of the quantification system the subcategory "feed and water" of the Biocheck Dairy is illustrated in Table 1.

These results are automatically generated after filling in the Biocheck questionnaire which is freely available at www.biocheck. ugent.be.

\subsubsection{Reporting of the biosecurity score}

The Biocheck system can be used anonymously and free of charge on the Biocheck website. Overall it takes between 20 and $45 \mathrm{~min}$ to fill in the questionnaire online after which the results are provided immediately. As it is also possible to use the scoring tool to assess the effect of changes in a farm or as a demonstration tool, the last question in the questionnaire is whether the provided results are based on a true farm or an exercise. In the latter situation, the data are not stored or used to calculate the averages per farm.

Based on the answers given in the questionnaire, the overall biosecurity score and the scores per subcategory are provided and compared to the average score of the country. Country specific averages are provided as soon as 40 records of this country are available. As long as this is not the case overall averages (based on all farms in the database) are provided (Figs. 2 and 3).

\subsection{Statistical analysis}

To evaluate the scoring system, the data from the 120 farms that participated in the previously mentioned survey (Renault et al., 2018a; Damiaans et al., 2019), was entered into the Biocheck scoring system and analyzed with the statistical package SPSS ${ }^{\circledR}$ Statistics 25.0. Basic descriptive analysis was executed to determine characteristics of the scores for each type of cattle and one-way ANOVA's were executed for each subcategory to determine differences between the three types. As 
"dairy management" cannot be compared over the different types, no ANOVA was performed for this subcategory. Although the residuals of five subcategories ("purchase and reproduction", "feed and water", "health management", "adult management" and "working organization and equipment") were not normally distributed according to the Shapiro-Wilk test, the histograms indicated that deviations from normality were limited. Therefore, following the central limit theorem and the expectation that with a larger sample size, most respondents would score about the mean with a low number of extreme scores, normality of the data was assumed. After performing a Levene's test, the variances were not equal for the subcategories of "purchase and reproduction", "feed and water", "visitors and employees" and "working organization". For these four subcategories a Welch ANOVA was performed. Post-hoc, a Tukey-Kramer was performed for the one-way ANOVA's to take the unequal sample size into account, and a Games-Howell was performed for the Welch ANOVA's. As the subcategories "calving management" and "adult management" only contained data for dairy and beef farms, a separate ANOVA was performed. Statistical significance was set at a p-value of 0.05 , while $\mathrm{p}$-values lower than 0.10 were considered borderline non-significant.

\section{Results}

The Biocheck Cattle contains 3 separate questionnaires that consist of 69 (veal), 104 (beef) and 124 (dairy) questions. The final weight of each subcategory was determined as the average of all experts' weights (Table 2). The experts considered external biosecurity to be equally important as internal biosecurity to estimate beef and dairy farms' biosecurity level. For veal farms, external biosecurity was assessed to be more important than internal biosecurity, so a $60 / 40$ ratio was adopted for the calculation of the final biosecurity score.

Table 3 contains the means of the Biocheck-scores for the 120 farms of each subcategory, internal and external biosecurity and the total score for veal, beef and dairy farms separately. The detailed description of the corresponding farms' application of biosecurity can be found in Damiaans et al. (2019) for the veal farms and in Renault et al. (2018a) for the beef and dairy farms, with a few examples used here as illustration.

\subsection{Veal farms}

Veal farms scored particularly low for "purchase", the highest weighted subcategory for external biosecurity. The maximum score for "purchase" obtained by a farm was 35 . The difference between the highest and lowest scores was only 30 points, showing the veal farms pursued very similar purchase policies. On all farms, the number of source farms was very high, whereas the time between start and end of filling the stable varied substantially.

The measures in the subcategory "transport and carcass removal" were well implemented. In none of the farms, transporters had access to the animals' living quarters and in $75 \%$ of the farms, transport vehicles were always cleaned and disinfected before entering the farm. Though a limited number of different visitors entered veal farms, the visitors who entered often did not implement measures such as passing through a hygiene lock and wearing farm specific boots and clothing. Even though three of the subcategories scored fairly high, each approaching 70 points, the score for external biosecurity was low (on average 41.2 points) due to the high influence of "purchase".

For internal biosecurity, especially the scores for "health management" were low, partly due to the lack of a physically separated hospital pen. The range of scores was limited, ranging from zero to 32 . The subcategory "working organization and equipment" scored relatively high and very similar among the veal farms, ranging from 47 to 68 points. Division in physically separated compartments was a common quality of most veal calf farms. A difference could be found in the maximum age difference within the compartments, partly explaining 


\begin{tabular}{|c|c|c|c|}
\hline & & $\begin{array}{l}\text { Score obtained by } \\
\text { farmer }\end{array}$ & $\begin{array}{l}\text { Average score of } \\
\text { participated farmers }\end{array}$ \\
\hline \multicolumn{4}{|c|}{ External biosecurity } \\
\hline 1 & Purchase and reproduction & $78 \%$ & $73 \%$ \\
\hline 2 & Transport and carcass removal & $49 \%$ & $49 \%$ \\
\hline 3 & Feed and water & $0 \%$ & $45 \%$ \\
\hline 4 & Visitors and employees & $51 \%$ & $52 \%$ \\
\hline \multirow[t]{2}{*}{5} & Vermin control and other animals & $65 \%$ & $53 \%$ \\
\hline & Subtotal external biosecurity & $58 \%$ & $59 \%$ \\
\hline \multicolumn{4}{|c|}{ Internal biosecurity } \\
\hline 1 & Health management & $31 \%$ & $24 \%$ \\
\hline 2 & Calving management & $49 \%$ & $47 \%$ \\
\hline 3 & Calf management & $49 \%$ & $47 \%$ \\
\hline 4 & Dairy management & $55 \%$ & $49 \%$ \\
\hline 5 & Adult management & $10 \%$ & $16 \%$ \\
\hline \multirow[t]{3}{*}{6} & Working organization and materials & $59 \%$ & $41 \%$ \\
\hline & Subtotal internal biosecurity & $43 \%$ & $38 \%$ \\
\hline & Total & $51 \%$ & $49 \%$ \\
\hline
\end{tabular}

Fig. 2. Online results in the Biocheck tool of a dairy farm after completing the questionnaire. Scores in red represent a score below the average.

the difference in scores for the subcategory. None of the subcategories of internal biosecurity scored high, yet especially the score for "health management" notably lowered the score for internal biosecurity to an average of 37.5 points. Overall, external biosecurity was slightly higher than internal biosecurity and the mean overall biosecurity score was 39.7 points.

\subsection{Beef farms}

In beef farms, the highest scoring subcategory in external biosecurity was "purchase and reproduction". This is partly due to the fact that $26 \%$ of the beef farms did not purchase animals at all. In those farms that did purchase animals, measures such as quarantine and checking the sanitary status of the farm of origin were often not or incorrectly implemented causing a large range in scores from 23 to 100 points. "Transport and carcass removal" was the second highest scoring subcategory with an average of 55.1 points. Measures concerning transport were variably implemented. Lowest scoring subcategory of external biosecurity was "feed and water" with an average score of 29.1. Few farms checked the quality of drinking water and safeguarded feed storages from contamination. Concerning the subcategory "visitors and employees, farm staff often wore farm specific boots and clothing, while visitors were less likely requested to take similar precautions. Veterinarians and artificial insemination technicians took these
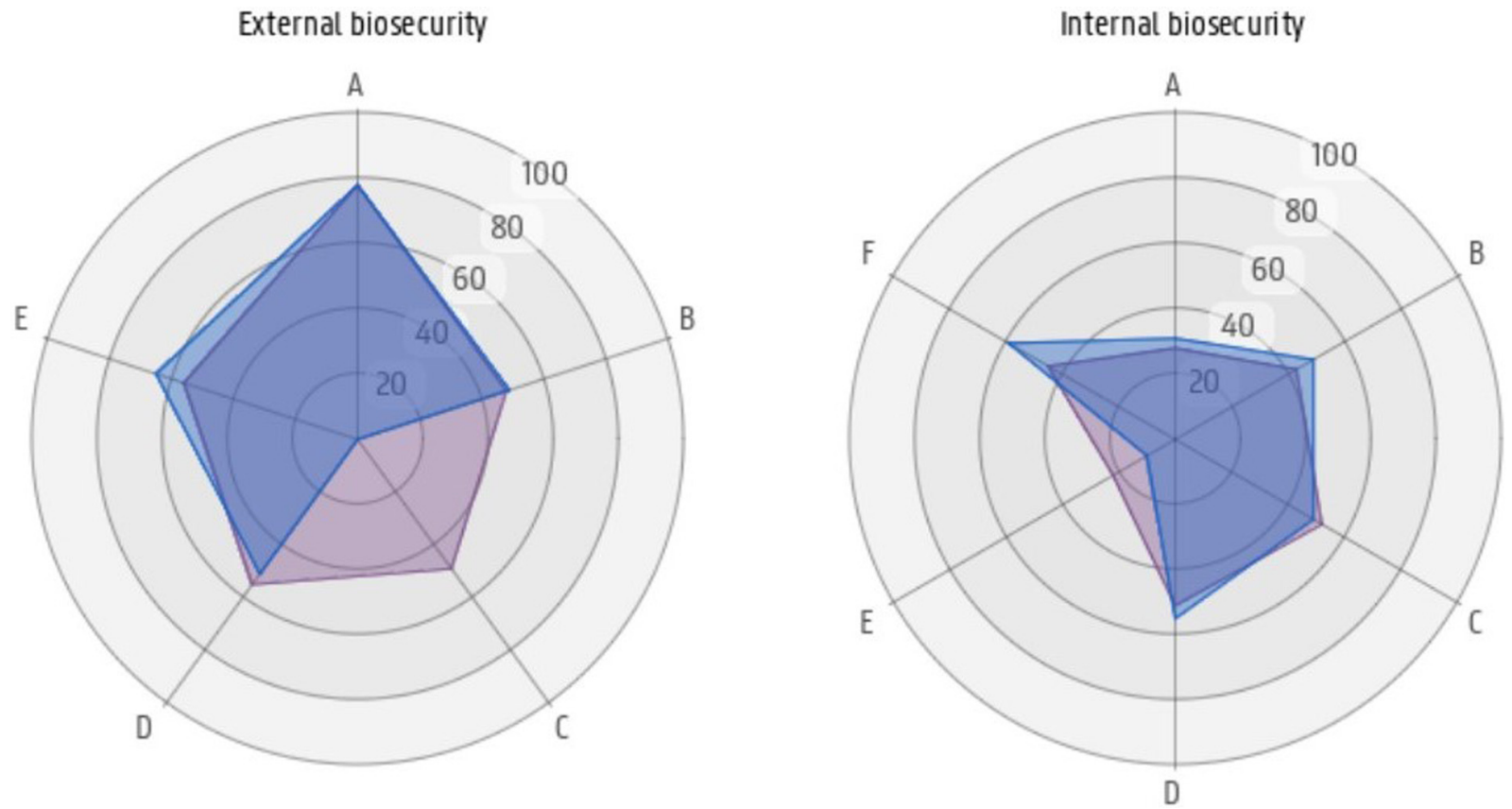

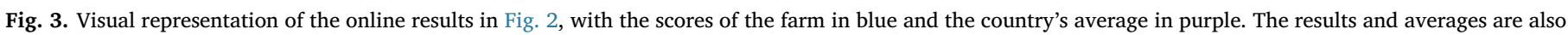

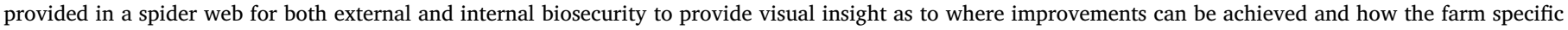
results relate to the country's average.gr3 
Table 2

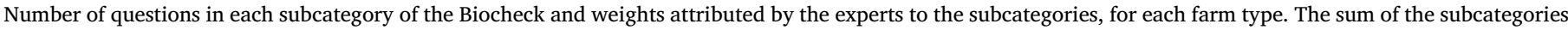
for both external and internal biosecurity add up to 100 points.

\begin{tabular}{|c|c|c|c|c|c|c|}
\hline & \multicolumn{2}{|l|}{ Veal } & \multicolumn{2}{|l|}{ Beef } & \multicolumn{2}{|l|}{ Dairy } \\
\hline & \#Questions & Score & \#Questions & Score & \#Questions & Score \\
\hline \multicolumn{7}{|l|}{ External biosecurity } \\
\hline Purchase and reproduction & 9 & 48 & 17 & 41 & 19 & 39 \\
\hline Transport and carcass removal & 11 & 16 & 11 & 18 & 11 & 17 \\
\hline Feed and water & 4 & 10 & 4 & 9 & 4 & 10 \\
\hline Visitors and employees & 9 & 15 & 13 & 19 & 13 & 20 \\
\hline Vermin control and other animals & 9 & 11 & 11 & 13 & 11 & 14 \\
\hline \multicolumn{7}{|l|}{ Internal Biosecurity } \\
\hline Health Management & 13 & 40 & 13 & 33 & 13 & 29 \\
\hline Calving management & / & / & 10 & 22 & 10 & 20 \\
\hline Calf management & 5 & 34 & 16 & 25 & 16 & 21 \\
\hline Dairy management & / & / & / & / & 17 & 13 \\
\hline Adult management & / & / & 2 & 10 & 3 & 7 \\
\hline Working organization and material & 9 & 26 & 7 & 10 & 7 & 10 \\
\hline
\end{tabular}

measures on $20-35 \%$ of the farms. In the subcategory "vermin control and other animals", vermin like rodents, insects and wild birds were considered a problem. Yet little to no farms had a standard control program to keep them out of the stables. In more than half of the farms, direct contact was possible with animals from other farms. In almost all farms pets had access to the stables. Three of the subcategories for external biosecurity varied between 50 and 55 points, resulting in a score for external biosecurity of 54.2 points.

As seen in the veal farms, "health management" was one of the lowest scoring subcategories of internal biosecurity with a mean of 28.6 points. This could be explained by the fact that very few farmers consistently isolate their sick animals. If sick animals were isolated, very few measures were taken to avoid indirect spread of infectious disease. Yet most farmers eliminated the carriers of infection that were detected. In the subcategory "calf management", only ten percent of the farmers administered four liters or more colostrum before the calves were six hours old. The colostrum was not checked for quality in any of the farms. Individual hutches for calf housing were cleaned in $30 \%$ of the farms, while group housing of older calves was never completely empty in half of the farms. "Adult management" including cleaning and disinfection of adult stables, scored the lowest with 14 points. With a mean score of 48.5 points, "working organization and equipment" scored highest on internal biosecurity for beef farms. In most farms the animals were grouped per age category, although the age groups were fully separated in only half of the farms. No additional measures were taken between age groups. The beef farms in this study scored 33.9 points for internal biosecurity on average. Through the combination of the scores for internal and external biosecurity, a total mean biosecurity score of
44.3 points was obtained for the beef farms.

\subsection{Dairy farms}

As in beef farms, in dairy farms "purchase and reproduction" was the highest scoring subcategory in external biosecurity. In dairy farms, this high score was due to the fact that many farms did not purchase cattle. Farms that did purchase generally took few extra measures to limit the risks, similar to beef farms and resulting in a large range of scores from 25 to 100 points. The lowest scoring subcategory in external biosecurity was "feed and water" with an average score of 45.9 points. Drinking water quality was often checked. Few farms protected the feed storages from pets and vermin. The subcategory "visitors and employees" scored second highest of all external biosecurity subcategories. Visitors had free access to the stables in two third of the farms, while they took no additional measures before entering. As in beef farms, veterinarians and artificial insemination technicians took additional measures more often than other visitors. Concerning the subcategory "vermin control and other animals", contact with cattle from other farms was possible in half of the farms, risking disease transmission through direct contact. Dogs were more often kept out of the stable than in beef farms, but cats were still able to enter the stables in almost all farms. The mean score calculated for external biosecurity added up to 58.9 points, the highest score for external biosecurity in the three types of cattle.

"Health management" was one of the lowest scoring subcategories in dairy farm internal biosecurity. Hospital pens were available in half of the farms, however sick animals were not physically isolated in most

Table 3

Mean, minimum, maximum and standard deviation of the Biocheck-scores for the 20 veal farms, 50 beef farms, 50 dairy farms separately.

\begin{tabular}{|c|c|c|c|c|c|c|c|c|c|c|c|c|}
\hline & \multicolumn{4}{|l|}{ Veal } & \multicolumn{4}{|l|}{ Beef } & \multicolumn{4}{|l|}{ Dairy } \\
\hline & Mean & Min & Max & SD & Mean & Min & Max & SD & Mean & Min & Max & SD \\
\hline Purchase and reproduction & 17.9 & 5 & 35 & 11.3 & 60.6 & 23 & 100 & 25.3 & 72.9 & 25 & 100 & 27.8 \\
\hline Transport and carcass removal & 69.1 & 30 & 94 & 17.7 & 55.1 & 12 & 87 & 16.2 & 49.3 & 13 & 87 & 17.2 \\
\hline Feed and water & 67.5 & 35 & 85 & 15.1 & 29.1 & 0 & 70 & 18.6 & 45.9 & 0 & 100 & 26.7 \\
\hline Visitors and employees & 49.4 & 13 & 94 & 25 & 53.7 & 24 & 85 & 13.5 & 52.2 & 27 & 98 & 16.6 \\
\hline Vermin control and other animals & 67.6 & 39 & 93 & 13.9 & 50.7 & 18 & 81 & 16.5 & 50.3 & 24 & 91 & 16.6 \\
\hline Health management & 13.1 & 0 & 32 & 7.8 & 28.6 & 7 & 64 & 12.2 & 24.3 & 8 & 42 & 9.3 \\
\hline Calving management & & & & & 46.6 & 5 & 81 & 18.5 & 46.9 & 6 & 73 & 15.6 \\
\hline Calf management & 50 & 17 & 79 & 17.3 & 31.8 & 7 & 73 & 17.6 & 46.6 & 13 & 72 & 15 \\
\hline Dairy management & & & & & & & & & 49 & 22 & 90 & 14.8 \\
\hline Adult management & & & & & 14 & 0 & 75 & 24.2 & 16.4 & 0 & 40 & 11.2 \\
\hline Working organization and equipment & 58.3 & 47 & 68 & 5.8 & 48.5 & 3 & 69 & 18.5 & 41.1 & 0 & 77 & 20.4 \\
\hline External biosecurity & 41.2 & 26 & 55 & 9.2 & 54.2 & 29 & 76 & 12.9 & 58.9 & 35 & 83 & 12.7 \\
\hline Internal biosecurity & 37.5 & 21 & 52 & 8.3 & 33.9 & 17 & 62 & 9.8 & 37.8 & 18 & 57 & 7.4 \\
\hline Total biosecurity & 39.7 & 26 & 51 & 7.4 & 44.3 & 24 & 69 & 8.4 & 48.6 & 31 & 69 & 8.1 \\
\hline
\end{tabular}


farms. Many farmers eliminated carriers of infection, but part of the farmers delayed the elimination, e.g. a cow with a persistent udder infection would be kept until the end of her lactation, increasing the possibility of transmission to other animals. Unlike on beef farms, calves were not always separated immediately. Other measures such as cleaning and disinfecting hands and obstetric equipment before each calving were well established among the participating dairy farms. In only four percent of the farms calves received the recommended four liters colostrum within the first six hours after being born. Most calves were housed in individual hutches that were cleaned and disinfected after use, resulting in an average score of 46.6 points for the subcategory "calf management". "Dairy management", the only subcategory specific for dairy farms was the highest scoring subcategory of internal biosecurity on dairy farms. Most farmers cleaned the teats prior to milking and disinfected them after. Few farmers milked the cows with mastitis or high somatic cell counts last. Only $20 \%$ of the farmers worked from young to old as milking the cows is the first action in the morning. Age groups were often divided into categories but not physically separated. None of the subcategories for internal biosecurity scored higher than 50 . The mean score for internal biosecurity was 37.8 , less than for external biosecurity, resulting in a total score for dairy biosecurity of 48.6 points.

\subsection{Comparison between the three types}

When comparing external biosecurity of the three types of cattle, the Welch ANOVA for "purchase and reproduction" was significant, meaning the three types significantly differed from each other (Table 4). Upon further comparison with the Games-Howell post hoctest the score for veal farms was significantly lower than for beef and dairy $(\mathrm{p}<0.01)$, while the difference between beef and dairy was borderline non-significant $(\mathrm{p}=0.06)$. In other subcategories, the veal farms scored significantly higher ( $\mathrm{p}<0.01$ for both (Welch) ANOVA and Games-Howell/Tukey Kramer post hoc-test), except for "visitors and employees" where no significant difference could be demonstrated between the three types. For "feed and water", the Games-Howell post hoc-test also indicated a significant difference $(\mathrm{p}<0.01)$ between beef and dairy, with dairy farms scoring higher than beef farms.

For internal biosecurity, a significant difference was found for "health management", "working organization and equipment" and "calf

\section{Table 4}

P-values of the ANOVA's and subsequent post hoc tests for the comparison between the different types of cattle farms. * represents the results of a Welch ANOVA. Significant and borderline non-significant ANOVA's were followed by a Tukey Kramer post hoc-test, significant Welch ANOVA's were followed by a Games-Howell post hoc-test. The subcategory Dairy management was removed, as it was exclusive to dairy farms.

\begin{tabular}{|c|c|c|c|c|}
\hline & \multirow{2}{*}{$\begin{array}{l}\text { ANOVA/ } \\
\text { Welch* }\end{array}$} & \multicolumn{3}{|c|}{ Post hoc-test } \\
\hline & & Veal-Beef & Veal-Dairy & Beef-Dairy \\
\hline & p-value & p-value & p-value & p-value \\
\hline Purchase and reproduction & $<0.01^{*}$ & $<0.01$ & $<0.01$ & 0.06 \\
\hline $\begin{array}{l}\text { Transport and carcass } \\
\text { removal }\end{array}$ & $<0.01$ & $<0.01$ & $<0.01$ & 0.20 \\
\hline Feed and water & $<0.01^{*}$ & $<0.01$ & $<0.01$ & $<0.01$ \\
\hline Visitors and employees & $0.72^{*}$ & & & \\
\hline $\begin{array}{l}\text { Vermin control and other } \\
\text { animals }\end{array}$ & $<0.01$ & $<0.01$ & $<0.01$ & 0.99 \\
\hline Health management & $<0.01$ & $<0.01$ & $<0.01$ & 0.09 \\
\hline Calving management & 0.95 & & & \\
\hline Calf management & $<0.01$ & $<0.01$ & 0.72 & $<0.01$ \\
\hline Adult management & 0.53 & & & \\
\hline $\begin{array}{l}\text { Working organization and } \\
\text { equipment }\end{array}$ & $<0.01^{*}$ & $<0.01$ & $<0.01$ & 0.14 \\
\hline External biosecurity & $<0.01$ & $<0.01$ & $<0.01$ & 0.14 \\
\hline Internal biosecurity & 0.06 & 0.27 & 0.99 & 0.07 \\
\hline Total biosecurity & $<0.01$ & 0.08 & $<0.01$ & 0.03 \\
\hline
\end{tabular}

management" ( $p<0.01)$. For "working organization and equipment", veal farms scored significantly higher than beef and dairy farms ( $p<0.01$ ), while they scored significantly lower for "health management" ( $p<0.01$ for both beef and dairy farms). Beef farms differed from dairy and veal farms $(\mathrm{p}<0.01)$ concerning "calf management", the beef farms scoring significantly lower. In the subcategories specific to dairy and beef farms, no significant difference could be demonstrated.

Although veal farms scored higher on three out of five subcategories for external biosecurity, due to their low scores for "purchase and reproduction" and its high impact on the score, veal farms scored significantly lower on external biosecurity $(\mathrm{p}<0.01)$. No significant difference could be demonstrated between dairy and beef farms. Differences between subcategories of internal biosecurity were less pronounced than in external biosecurity. A significant difference for the total biosecurity score between dairy and beef farms $(p=0.03)$ and dairy and veal farms $(\mathrm{p}<0.01)$ was noted, with dairy farms scoring significantly higher. The Tukey Kramer post hoc-test between veal and beef farms was borderline non-significant ( $p=0.08)$.

\section{Discussion}

Although risk factor studies considering the efficiency of biosecurity measures for single diseases have been performed (Al Mawly et al., 2015; Delafosse et al., 2015; Tarazi and Abo-Shehada, 2015), the overall level of biosecurity is still largely unknown in cattle. In this study, a risk-based evaluation tool was developed to assess the implementation of biosecurity on cattle farms by quantifying the level of biosecurity in a standardized and reproducible manner. In the study, this tool was also used to assess biosecurity levels in Belgian veal, beef and dairy farms.

By quantitatively assessing biosecurity, the Biocheck scoring system indicates possible areas of improvement and allows for benchmarking of farms and comparison with peers. These aspects can motivate farmers to improve their biosecurity. With this tool it is possible to differentiate between farms based on the implemented biosecurity measures and their relative importance instead of the number of measures implemented. Benchmarking in the Biocheck system is established by comparing the own results to the national or international averages.

As with every scoring tool, the presented Biocheck system has some limitations. The weights attributed to the biosecurity measures could be a subjective assessment of their importance, influenced by the experts' opinion. However, this effect was limited as much as possible by the stepwise development based upon a thorough literature search and the estimation of the weights by an expert panel. This methodology has already been applied previously for the development of the Biocheck scoring systems for pigs and broilers (Laanen et al., 2013; Gelaude et al., 2014). Also the completeness of the list of biosecurity measures included could be discussed. Yet it was attempted to include all major risks and at the same time limit the number of questions to keep the use of the system workable in the field.

As "purchase and reproduction" was weighed almost twice as high as the second highest scoring subcategory, it has a high influence on the score of external biosecurity. The first question of the subcategory, whether animals are purchased or not, has a high influence on its score, as the subsequent questions are dependent on it (e.g. how often do you purchase animals). Consequently, it also has a large influence on the score of external biosecurity. Besides, purchase is an important and highly cited risk factor for cattle diseases in literature (Maunsell and Donovan, 2009; Dias et al., 2013; Amelung et al., 2018). The subcategory "visitors and employees" was considered less important in veal than in beef and dairy farms, possibly because less types of visitors enter veal farms (Damiaans et al., 2019).

For internal biosecurity the subcategory "health management" was considered the most important, though the differences in scoring were not as high as in external biosecurity. The importance of health 
management is confirmed by Wells et al. (2002) who stated that infected animals are a major reservoir of infection and contact with healthy animals should be avoided. None of the questions in the subcategories had a high influence on the internal or final biosecurity score.

In veal farms, external biosecurity was considered more important than internal biosecurity for the final score, considering the risk of purchasing new calves of different origin each production cycle.

It's logical that in the subcategories with a low number of questions, each question has a higher influence on the score of the subcategory. This also means these subcategories could have more extreme scores, either high or low, as can be seen in the scores for "adult management" and "feed and water" in dairy and beef farms.

The precaution of not awarding points to the intermediate answer is taken because experience in the existing Biocheck systems has learned that users desire to answer "sometimes" even if the measure is only implemented seldom. It may seem severe, yet giving the lowest score provides an opportunity for improvement when the tool is used as a starting point for counseling towards improved biosecurity.

It is important to realize that even though the farms were randomly selected, they could refuse to participate resulting in a possible selection bias towards more motivated or more knowledgeable farmers. This may lead to a higher score in the sample compared to the actual population. However, as the biosecurity scores in the study can overall be considered low, there is ample room for improvement in both the sample and the population. Variation in the execution of most measures is high, showing improvement is possible on almost all aspects of biosecurity.

Although there are constraints to compare the different production systems, the results of our study clearly demonstrate that each farm type has its own biosecurity strengths and challenges. This difference also illustrates that biosecurity advice should be sector-specific in order to be relevant.

In general, the scores for external biosecurity were higher than internal biosecurity, which is in concordance with results of the Biocheck.UGent for pigs (Laanen et al., 2013). This might be explained by the fact that, following epidemic disease outbreaks and the implementation of national eradication programs for bovine viral diarrhea and infectious bovine rhinotracheitis (KB2017-09-18/09 Royal Decree, 2017; KB2018-04-27/03 Royal Decree, 2018), sensitization of external biosecurity measures was performed, while information about internal biosecurity measures was less emphasized. Also, external biosecurity measures are more often mandatory and concern the involvement of external parties, while internal biosecurity measures concern the habits of the farmer (Laanen et al., 2010).

The low mean scores for both external and internal biosecurity show that there is ample room for improvement in all types. For external biosecurity, even though the purchase policy may differ between the farm types, purchasing cattle is always a risk for disease introduction (Boelaert et al., 2005; Hotchkiss et al., 2011; Dias et al., 2013; Cuttance and Cuttance, 2014). Beef and dairy farms not keeping a closed farm scored very low (min. 23, resp. 25 points), showing many biosecurity measures concerning purchase were not implemented (Mee et al., 2012; Pardon, 2012; Sarrazin et al., 2014; Damiaans et al., 2018). This means the farms that do purchase take few measures to reduce the risks, as described by Renault et al. (2018a) where only $13 \%$ of dairy farms and $30 \%$ of beef farms applied quarantine. The significantly higher score for other subcategories of external biosecurity in veal farms suggest that other measures are taken to compensate for the weaker purchase policy. It also provides the opportunity for dairy and beef farms to improve by learning from the strong points of veal farms.

For internal biosecurity, "health management" was considered the most important subcategory by the experts, while scoring very low in the participating farms. Still, it is of the utmost importance to avoid contact of healthy cattle with infected animals, as the latter is a major reservoir of infection (Wells et al., 2002; Saegerman and Humblet,
2018). To implement an effective health management system on a farm, management decisions should be based on recorded information about the concerned animals (such as age, sex, previous diseases and therapies) and diseases (such as morbidity, mortality, treatment, carriers) (Lechtenberg et al., 1998). This data was not available on most farms.

Good calving management is considered an important part of biosecurity to reduce perinatal mortality and morbidity (Svensson et al., 2003; Mee, 2004, 2008; Damiaans et al., 2018). Therefore, the relatively high scores for calving management and the presence of a high number of individual maternity pens on the participating farms are positive. However, often the maternity pens were not separated from other animals. A group maternity pen can also serve as an indirect source of infection if not properly cleaned and disinfected between two parturitions or used as a hospital pen (Fossler et al., 2005a, b).

Even though only two subcategories were significantly different between dairy and beef farms, the total biosecurity scores of dairy farms were significantly higher than those of both beef and veal farms. A possible explanation is that while the differences were too small to be significant for the separate subcategories, they stacked and revealed the difference in the total score, indicating a higher overall biosecurity level in the participating dairy farms.

In pig production, the link between biosecurity and animal production, antimicrobial usage and resistance has been established (Postma et al., 2016). In future studies, the tool developed in this study can be used to explore the relationships between biosecurity, health parameters, production characteristics and parameters such as antimicrobial use and resistance for cattle production.

Although the Biocheck Cattle tool was developed and validated in Belgian farms, the system is built on universal biosecurity principles and can be utilized worldwide in all farms with comparable management systems. The main focus of the tool was on farms with an intensive production system, yet the principles of biosecurity on which it was based, apply to extensive production systems as well.

In conclusion, the tool developed in this study can be used for assessing the biosecurity level of a farm in an objective and repeatable manner. It also allows to compare farms both with their peers and in time. Although differences can be found between the three production types, there is room for improvement concerning biosecurity in all three farm types in Belgium.

\section{Research data}

All research data are available with the author.

\section{Funding}

This study was supported by the Belgian Federal Public Service for Health, Food Chain Safety and Environment (Contract RT 15/4 BOBIOSEC1). The funding source had no other involvement.

\section{Transparency declaration}

The lead author affirms that this manuscript is an honest, accurate, and transparent account of the study being reported; that no important aspects of the study have been omitted; and that any discrepancies from the study as planned (and, if relevant, registered) have been explained.

\section{Declaration of Competing Interest}

The authors declare no conflict of interest.

\section{Acknowledgments}

This study was supported by the Belgian Federal Public Service for Health, Food Safety and Environment (Contract RT 15/4 BOBIOSEC1). 
We would also like to thank all the farmers involved in this study for their collaboration.

\section{Appendix A. Supplementary data}

Supplementary material related to this article can be found, in the online version, at doi:https://doi.org/10.1016/j.prevetmed.2020. 104992.

\section{References}

Al Mawly, J., Grinberg, A., Prattley, D., Moffat, J., Marshall, J., French, N., 2015. Risk factors for neonatal calf diarrhoea and enteropathogen shedding in New Zealand dairy farms. Vet. J. 203, 155-160.

Amelung, S., Hartmann, M., Haas, L., Kreienbrock, L., 2018. Factors associated with the bovine viral diarrhoea (BVD) status in cattle herds in Northwest Germany. Vet. Microbiol. 216, 212-217.

Boelaert, F., Speybroeck, N., Kruif, Ad., Aerts, M., Burzykowski, T., Molenberghs, G., Berkvens, D.L., 2005. Risk factors for bovine herpesvirus-1 seropositivity. Prev. Vet. Med. 69, 285-295.

Brennan, M.L., Christley, R.M., 2013. Cattle producers' perceptions of biosecurity. BMC Vet. Res. 9, 71.

Cuttance, W., Cuttance, E., 2014. Analysis of individual farm investigations into bovine viral diarrhoea in beef herds in the North Island of New Zealand. N. Z. Vet. J. 62, 338-342.

Damiaans, B., Sarrazin, S., Heremans, E., Dewulf, J., 2018. Perception, motivators and obstacles of biosecurity in cattle production. Vlaams Tijdschr. 87, 150-163.

Damiaans, B., Renault, V., Sarrazin, S., Berge, A.C., Pardon, B., Ribbens, S., Saegerman, C., Dewulf, J., 2019. Biosecurity practices in Belgian veal calf farming: level of implementation, attitudes, strengths, weaknesses and constraints. Prev. Vet. Med. 172, 104768.

Daugschies, A., Najdrowski, M., 2005. Eimeriosis in cattle: current understanding. J. Vet. Med. Ser. B 52, 417-427.

Delafosse, A., Chartier, C., Dupuy, M.C., Dumoulin, M., Pors, I., Paraud, C., 2015. Cryptosporidium parvum infection and associated risk factors in dairy calves in western France. Prev. Vet. Med. 118, 406-412.

Dewulf, J., Van Immerseel, F., 2018. General principles of biosecurity in animal production and veterinary medicine. In: Dewulf, J., Van Immerseel, F. (Eds.), Biosecurity in Animal Production and Veterinary Medicine. Acco, Ghent, Belgium, pp. 63-76.

Dias, J.A., Alfieri, A.A., Ferreira-Neto, J.S., Goncalves, V.S., Muller, E.E., 2013. Seroprevalence and risk factors of bovine herpesvirus 1 infection in cattle herds in the state of Parana. Brazil. Transbound Emerg Dis 60, 39-47.

Enting, H., Kooij, D., Dijkhuizen, A., Huirne, R., Noordhuizen-Stassen, E., 1997. Economic losses due to clinical lameness in dairy cattle. Livest. Prod. Sci. 49, 259-267.

European Council Regulation, 2016. Regulation (EU) 2016/429 of the European Parliament and of the Council of 9 March 2016 on transmissible animal diseases and amending and repealing certain acts in the area of animal health ('Animal Health Law'). Official Journal of the European Union. 1-208.

Fossler, C.P., Wells, S.J., Kaneene, J.B., Ruegg, P.L., Warnick, L.D., Bender, J.B., Eberly, L.E., Godden, S.M., Halbert, L.W., 2005a. Herd-level factors associated with isolation of Salmonella in a multi-state study of conventional and organic dairy farms I. Salmonella shedding in cows. Prev. Vet. Med. 70, 257-277.

Fossler, C.P., Wells, S.J., Kaneene, J.B., Ruegg, P.L., Warnick, L.D., Bender, J.B., Eberly, L.E., Godden, S.M., Halbert, L.W., 2005b. Herd-level factors associated with isolation of Salmonella in a multi-state study of conventional and organic dairy farms II. Salmonella shedding in calves. Prev. Vet. Med. 70, 279-291.

Gelaude, P., Schlepers, M., Verlinden, M., Laanen, M., Dewulf, J., 2014. Biocheck. UGent: a quantitative tool to measure biosecurity at broiler farms and the relationship with technical performances and antimicrobial use. Poult. Sci. 93, 2740-2751.

Gore, S.M., 1987. Biostatistics and the medical research council. Medical Research Council News 35, 19-20.

Gunn, G., Heffernan, C., Hall, M., McLeod, A., Hovi, M., 2008. Measuring and comparing constraints to improved biosecurity amongst GB farmers, veterinarians and the auxiliary industries. Prev. Vet. Med. 84, 310-323.

Hotchkiss, E.J., Hodgson, J.C., Schmitt-van de Leemput, E., Dagleish, M.P., Zadoks, R.N., 2011. Molecular epidemiology of Pasteurella multocida in dairy and beef calves. Vet. Microbiol. 151, 329-335.

Houe, H., 1999. Epidemiological features and economical importance of bovine virus diarrhoea virus (BVDV) infections. Vet. Microbiol. 64, 89-107.

Humphry, R., Brlisauer, F., McKendrick, I., Nettleton, P., Gunn, G., 2012. Prevalence of antibodies to bovine viral diarrhoea virus in bulk tank milk and associated risk factors in Scottish dairy herds. Veterinary Record-English Edition 171, 445.

KB2017-09-18/09, Royal Decree, 2017. Koninklijk Besluit Betreffende De Bestrijding Van Boviene Virale Diarree. Belgium. .

KB2018-04-27/03, Royal Decree, 2018. Koninklijk Besluit Tot Wijziging Van Het Koninklijk Besluit Van 25 November 2016 Betreffende De Bestrijding Van Infectieuze Boviene Rhinotracheïtis. Belgium. .

Laanen, M., Beek, J., Ribbens, S., Vangroenweghe, F., Maes, D., Dewulf, J., 2010. Biosecurity on pig herds: development of an on-line scoring system and the results of the first 99 participating herds. Vlaams Tijdschr. 79, 302-306.

Laanen, M., Persoons, D., Ribbens, S., de Jong, E., Callens, B., Strubbe, M., Maes, D., Dewulf, J., 2013. Relationship between biosecurity and production/antimicrobial treatment characteristics in pig herds. Vet. J. 198, 508-512.

Lechtenberg, K.F., Smith, R.A., Stokka, G.L., 1998. Feedlot health and management. Veterinary Clinics: Food Animal Practice 14, 177-197.

Lin, J., Kaphle, K., Wu, L., Yang, N., Lu, G., Yu, C., Yamada, H., Rogers, P., 2003. Sustainable veterinary medicine for the new era. Revue scientifique et techniqueOffice international des épizooties 22, 949-964.

Maunsell, F.P., Donovan, G.A., 2009. Mycoplasma bovis Infections in young calves. Vet. Clin. North Am. Food Anim. Pract. 25, 139-177 vii.

Mee, J.F., 2004. Managing the dairy cow at calving time. Veterinary Clinics: Food Animal Practice 20, 521-546.

Mee, J., 2008. Prevalence and risk factors for dystocia in dairy cattle: a review. Vet. J. 176, 93-101.

Mee, J.F., Geraghty, T., O’Neill, R., More, S.J., 2012. Bioexclusion of diseases from dairy and beef farms: risks of introducing infectious agents and risk reduction strategies. Vet. J. 194, 143-150.

Mellor, D., Stafford, K., 2004. Animal welfare implications of neonatal mortality and morbidity in farm animals. Vet. J. 168, 118-133.

Nöremark, M., Frössling, J., Lewerin, S.S., 2010. Application of routines that contribute to on-farm biosecurity as reported by swedish livestock farmers. Transbound. Emerg. Dis. 57, 225-236.

Nöremark, M., Sternberg Lewerin, S., Ernholm, L., Frössling, J., 2016. Swedish farmers' opinions about biosecurity and their intention to make professionals use clean protective clothing when entering the stable. Front. Vet. Sci. 3, 46.

Pardon, B., 2012. Morbidity, Mortality and Drug Use in White Veal Calves With Emphasis on Respiratory Disease. Ghent University. .

Postma, M., Dewulf, J., 2018. Biosecurity and its relationship with health, production and antimicrobial use. Biosecurity in animal production and veterinary medicine: from principles to practice. ACCO 77-94.

Postma, M., Backhans, A., Collineau, L., Loesken, S., Sjölund, M., Belloc, C., Emanuelson, U., Beilage, E.G., Stärk, K., Dewulf, J., 2016. The biosecurity status and its associations with production and management characteristics in farrow-to-finish pig herds. animal 10, 478-489.

Rehman, T.U., Khan, M.N., Sajid, M.S., Abbas, R.Z., Arshad, M., Iqbal, Z., Iqbal, A., 2011 Epidemiology of Eimeria and associated risk factors in cattle of district Toba Tek Singh. Pakistan. Parasitology research 108, 1171-1177.

Renault, V., Damiaans, B., Sarrazin, S., Humblet, M.F., Dewulf, J., Saegerman, C., 2018a Biosecurity practices in Belgian cattle farming: level of implementation, constraints and weaknesses. Transbound. Emerg. Dis. 65 (5), 1246-1261.

Renault, V., Damiaans, B., Sarrazin, S., Humblet, M.F., Lomba, M., Ribbens, S., Riocreux, F., Koenen, F., Cassart, D., Dewulf, J., 2018b. Classification of adult cattle infectious diseases: a first step towards prioritization of biosecurity measures. Transbound. Emerg. Dis. 65 (6), 1991-2005.

Saegerman, C., Humblet, M.-F., 2018. Biosecurity in veterinary practices and clinics. Biosecurtiy in animal production and veterinary medicine 453-474.

Sarrazin, S., Cay, A.B., Laureyns, J., Dewulf, J., 2014. A survey on biosecurity and management practices in selected Belgian cattle farms. Prev. Vet. Med. 117, 129-139.

Sarrazin, S., Damiaans, B., Renault, V., Saegerman, C., 2018. Transmission of cattle diseases and biosecurity in cattle farms. Biosecurtiy in animal production and veterinary medicine 357-408.

Sayers, R., Good, M., Sayers, G., 2014. A survey of biosecurity-related practices, opinions and communications across dairy farm veterinarians and advisors. Vet. J. 200, 261-269.

Svensson, C., Lundborg, K., Emanuelson, U., Olsson, S.-O., 2003. Morbidity in Swedish dairy calves from birth to 90 days of age and individual calf-level risk factors for infectious diseases. Prev. Vet. Med. 58, 179-197.

Tarazi, Y.H., Abo-Shehada, M.N., 2015. Herd- and individual-level prevalences of and risk factors for Salmonella spp. Fecal shedding in dairy farms in Al-Dhulail Valley. Jordan. Tropical Animal Health and Production 47, 1241-1248.

Villarroel, A., Dargatz, D.A., Lane, V.M., McCluskey, B.J., Salman, M.D., 2007. Suggested outline of potential critical control points for biosecurity and biocontainment on large dairy farms. J. Am. Vet. Med. Assoc. 230, 808-819.

Wells, S.J., Dee, S., Godden, S., 2002. Biosecurity for gastrointestinal diseases of adult dairy cattle. Vet. Clin. North Am. Food Anim. Pract. 18, 35-55. 